\title{
The opportunity matrices for chain innovative transformation of economy: the CITE concept
}

\author{
T.I. Vorobets ${ }^{1}$, V.V. Oberemok ${ }^{1}$ \\ ${ }^{1}$ V.I. Vernadsky Crimean Federal University
}

\begin{abstract}
The arsenal of methods available to economics can be enriched by examining its problems from different points of view and using technologies developed from complex natural systems. In this study, using the example of the creation of opportunity matrices, we describe a method for chain innovative transformation of economic processes using an intersectoral GDP matrix directly analogous to the DNA matrix in the polymerase chain reaction that revolutionized molecular biology. The idea behind the creation of the GDP matrix is to obtain innovative products and opportunity matrices, which will be formed by chains of sectors of the economy using the following algorithm. The most innovatively developed sectors of the economy are located at the edges of the GDP matrix according to the queue (for example, 1-3-5-7-8-6-4-2). In such a scheme, innovatively less developed sectors of the economy, located in the middle of the GDP matrix, have the most contacts, which give them the opportunity to gain more skills and abilities. The most distal sectors of the matrix have fewer contacts, but in view of greater economic development, they will generate the innovative ideas and be the last link forming or receiving the end-product. Each newly formed opportunity matrix (GDP') can serve as a template for the creation of new innovative ideas and products. Using the proposed approach, the economic miracles of Singapore, South Korea, and Hong Kong are considered along with the prospect of innovative development for African countries that have not yet undergone industrialization.
\end{abstract}

\section{Introduction}

Economic systems are continuously becoming more complex. The methods used to describe them are also complex, which is the basis for the study of the theory of networks, nonlinear dynamics, and complex systems with suddenly arising properties that are not susceptible to conjectures and that contradict reductionism. This is the direct result of the scientific and technical progress and innovations that provide economic systems with additional opportunities for growth and development. For example, the introduction of computer technologies and networks into economics allows us to reach a qualitatively new level of efficiency in the organization of economic processes, particularly through automation and robotization of business processes. Over the long-term, many achievements have been made in economics; however, despite the multitude of studies and research that describe economic processes and their patterns, modern economic dynamics require new, combined, and most importantly visual and effective approaches to decision making, which will save time and, accordingly, reduce the likelihood of lost profits.

\section{Body}

With the progressive growth of the global economy and the concomitant onset of economic crises, there is an urgent need to forecast and model economic processes to form a strategy for sustainable development, balancing active government regulation and economic liberalism. The possibility to foresee and resolve a sudden situation has always been valued in economic theory. Unfortunately, in the course of economic analysis it is not possible to conduct controlled experiments. In our opinion, 
the solution to this problem may be the use of convergent technologies developed from natural systems that have proven themselves in areas other than the economy, where experimentation is applicable. In this paper, we propose to use the polymerase chain reaction (PCR) method, which is widely used in molecular biology, for the modelling of economic processes. This is a method used in the laboratory for the rapid cloning of a specific region of DNA, which in turn has a direct analogy with cellular DNA replication in biology and nuclear reactions in physics. We noticed that, in many respects, the main components of the PCR reaction mixture have direct analogues in economic processes, and that the principle of polymerase chain reaction can be successfully applied to describe some economic processes, including the incremental growth of the economic potential of a country.

To begin with, we would like to more deeply draw an analogy between the convergent approach we are proposing for a chain-based innovative transformation of the economy (CITE) using the example of the revolutionary method used in molecular biology - PCR.

Polymerase chain reaction is a method of rapid cloning (amplification) of a specific section of DNA in vitro during a programmed run of 30-40 cycles (Saiki et al., 1988). Polymerase chain reaction was invented by the American biochemist Kary Mullis in 1983. The availability and simplicity of PCR have made this method an indispensable application in various areas of molecular genetics research. The concept of PCR is based on the DNA template and short DNA fragments (primers) that limit the amplification region.

Each PCR cycle consists of three stages: denaturation (separation of the complementary strands of DNA strands), annealing of primers (attachment to the DNA strands), and chain synthesis carried out by the DNA polymerase enzyme. The number of amplicons formed during PCR can be found by the following formula: $A=\left(2^{n}-2 n\right) \times k$, where $n$ is the number of cycles and $k$ is the number of DNA matrices. Based on the formula, if there is one DNA template, the first two amplicons (the target PCR product) appear in the $3^{\text {rd }}$ cycle. In the following cycles, the amplicons formed serve as matrices for the synthesis of new amplicons, which is why the reaction is called a chain reaction (Fig. 1).
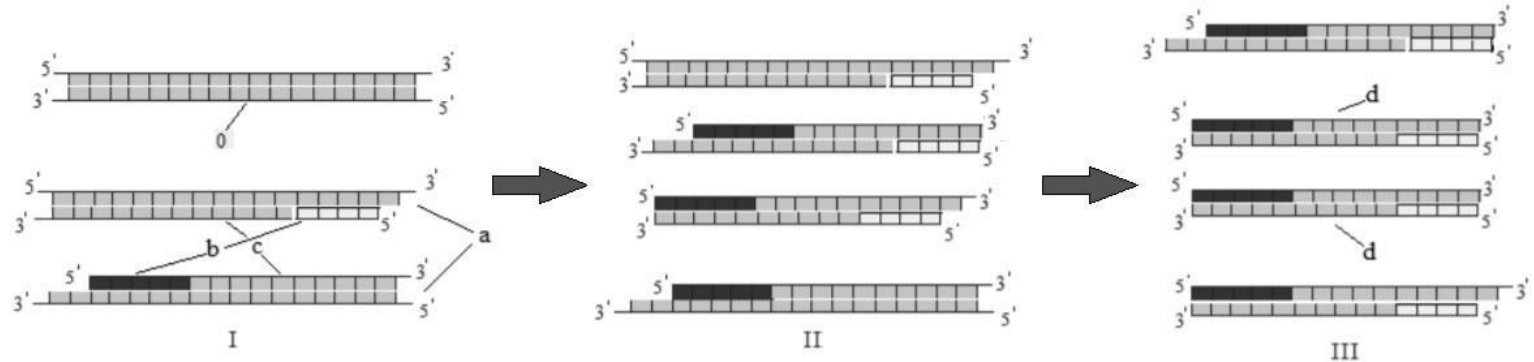

Fig. 1. PCR scheme: I, II, III ( $1^{\text {st }}, 2^{\text {nd }}$ and $3^{\text {rd }}$ cycles $) ; 0$ - DNA matrix; $d$ - amplicons. The PCR cycle includes: $\mathrm{a}$ - denaturation, $\mathrm{b}$ - primer annealing, $\mathrm{c}$ - chain synthesis.

Now, similar to the DNA matrix, we will create a matrix for the chain innovative transformation of the economy (CITE). Drawing an analogy with respect to the economy, there is a category without the existence of which it is difficult to imagine the functioning of any country. This is the gross domestic product (GDP), the total current market value of all final goods and services produced by the economy of a country over a certain period of time with the participation of all types of production within the national territory. All sectors of the economy associated with the consumption and accumulation of inventory values are taken into account, including exports, thus the GDP indicator includes all information about the structure of a nation's economy.

In our opinion, in the $21^{\text {st }}$ century, the GDP matrix should be built based on the innovative potential of the country as the main source of GDP growth. The idea behind the creation of the GDP matrix is 
to obtain innovative products and opportunity matrices, which will be formed by chains of sectors of the economy using the following algorithm. The most innovatively developed sectors of the economy are located at the edges of the GDP matrix according to the queue (for example, 1-3-5-7-8-6-4-2). In such a scheme, innovatively less developed sectors of the economy, located in the middle of the GDP matrix, have the most contacts, which give them the opportunity to gain more skills and abilities ( $\uparrow$ : high innovative growth; $\downarrow$ : low innovative growth). The most distal sectors of the matrix have fewer contacts, but in view of greater economic development, they will generate the innovative ideas and be the last link forming or receiving the end-product (Fig. 2). Thus, the extreme sectors of the GDP matrix are analogues of the primers in PCR and limit the scope of innovation amplification (Fig. $1)$.

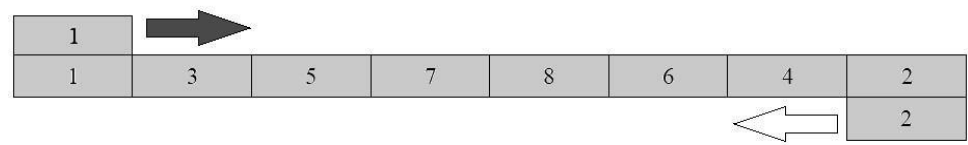

Fig. 2. Algorithm for constructing a GDP matrix using the example of 8 industries.

As a result, there is a progression (amplification) in the growth of the economic potential of the country with the advent of each new innovative product, i.e., there is an increase in new knowledge and skills (especially in the lagging sectors of the economy) with each new cycle of CITE, which leads to an increase in the number of opportunity matrices in the innovation aspect. Each newly formed matrix can serve as a basis for new ideas and products, i.e., the formed opportunity matrix (GDP') shows the ability to grow, and is similar to the amplicon in PCR.

It should be noted that the ranking proposed by us (Fig. 2) is not strict, but rather desirable, and other options for constructing a GDP matrix are possible (the $1^{\text {st }}$ principle of the CITE concept); for example, a full matrix: 1-5-7-6-8-4-2-3, or a shortened one: 5-6-8-7-3. Presented in Fig. 3, the topological scheme helps to clearly demonstrate that the most economically efficient situation occurs in the $2^{\text {nd }}$ case, when the incremental growth occurs according to the formula $3^{\mathrm{n}}$, where $\mathrm{n}$ is every other innovative cycle. In this instance, the most favourable conditions are created (a powerful flow of cash and innovations), which leads to their constant increase during the transition from sector to sector. This flow is created by the desire of sectors to make a profit. To us, this aspiration is analogous to a protein catalyst (DNA polymerase) in PCR. As a result, a new chain is being built, a new matrix leading to the formation of the next innovative product. Such a newly formed GDP matrix (or opportunity matrix) is a derivative of the original GDP matrix, with the difference that it has a higher potential to create a certain product and can be used to create another innovative product or an improved version of the previous one.

Since in the $2^{\text {nd }}$ case the chain functions both in the forward $(1 \rightarrow 3 \rightarrow 5 \rightarrow 7 \rightarrow 8 \rightarrow 6 \rightarrow 4 \rightarrow 2)$ and in the opposite $(1 \leftarrow 3 \leftarrow 5 \leftarrow 7 \leftarrow 8 \leftarrow 6 \leftarrow 4 \leftarrow 2)$ direction, any new GDP' matrix (or opportunity matrix) formed can also work in both directions. This is due to the fact that the initial GDP matrix was innovatively growing in both directions; therefore, it will always be necessary to make small changes and implement modernization to continue producing new innovative products in both directions.

The most realistic situation is that of the $3^{\text {rd }}$ case, when the growth of a new GDP' matrix does not occur from the very edge. It should be noted here that the middle portion (intersection) of the formed matrices grows most powerfully, according to the formula $2^{n+1}-1$, and represents the 'hot' spot of innovations. If in the next set of cycles, the GDP matrix launches new innovative products formed within this 'hot' spot in both directions, as presented in the $2^{\text {nd }}$ case, this will lead to an increase in the innovation potential of the median area according to the $3^{n}$ formula. Cases 1 and 4 , where the 
$8^{\text {th }}$ International Conference on Management, Economics and

Humanities

7 - 9 December, 2018

Barcelona, Spain

growth of the innovation potential is based on the $2^{\mathrm{n}}$ formula, are the least productive, but clearly show that, to obtain an innovative product, the longest intersectoral chain possible should be used, which should function in both directions with the formation of an intersection to create the maximum effect. Again, it should be noted that CITE does not force the economy to function in this way, but it clearly demonstrates how to optimize the incremental growth of the innovative potential of a country depending on the situation (the $2^{\text {nd }}$ principle of the CITE concept).

It should also be noted that one of the most important properties of GDP matrices is their fractal nature. The fractality of GDP matrices is the ability of each individual segment of a matrix (cluster, enterprise, team of employees) to repeat in its functioning and development the properties of the entire matrix as a whole and to be reproduced at different scales with inherent features at each level. Thus, while each GDP matrix has its own dimension (national economy, cluster economy, enterprise), it retains at the same time all of its inherent functional properties. The structure of the GDP matrix is not constant and may become obsolete, thereby requiring its further evolutionary development (or adaptation). Such development may be manifested by the formation of new sectors of the economy or a significant improvement in the old ones. Each individual opportunity matrix (GDP') is a variant of the initial GDP matrix and is formed as the result of a chain innovation transformation based on the national economy. The total result of the functioning opportunity matrices at a certain point in time forms the total GDP matrix of the country. 


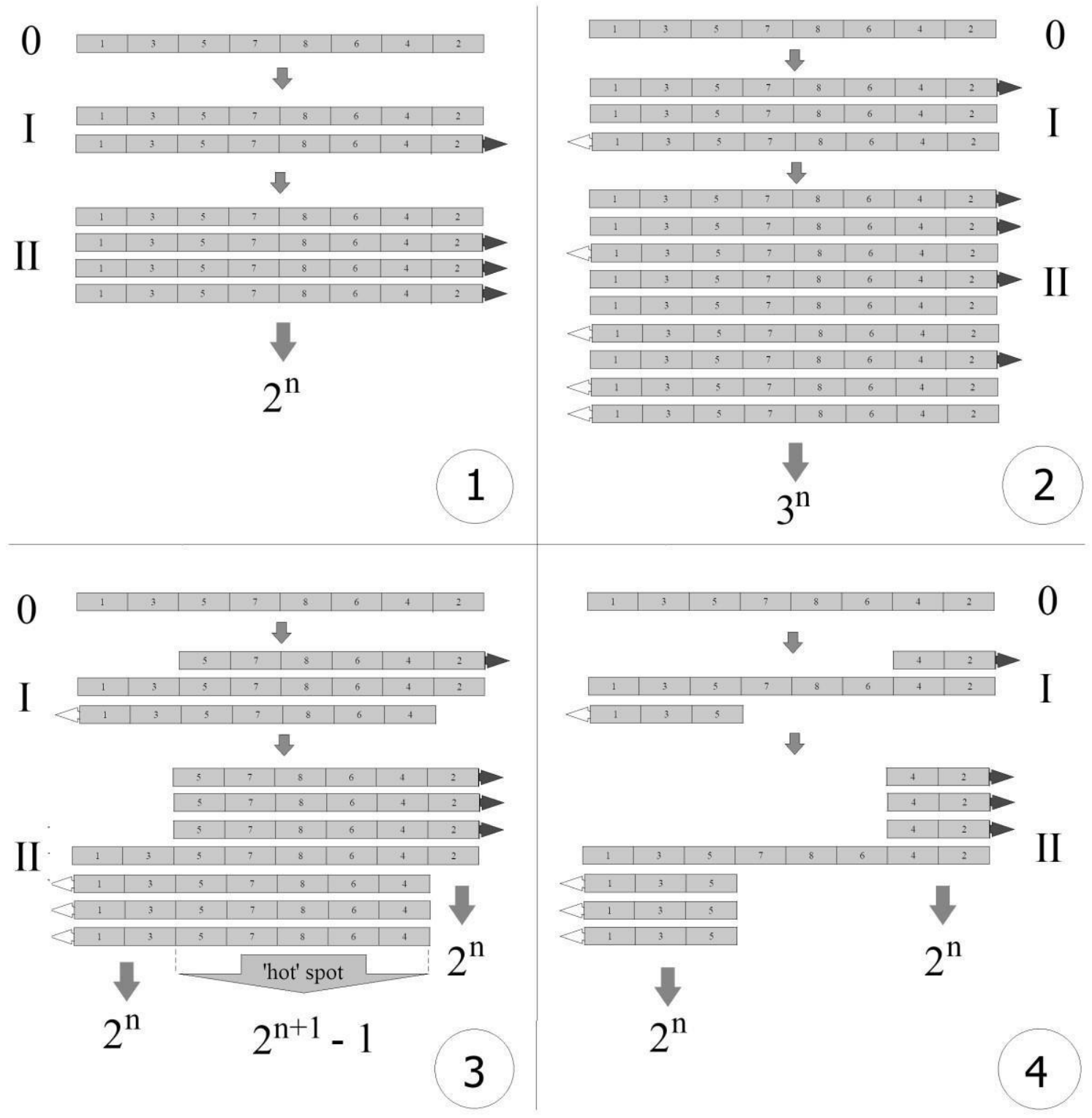

Fig. 3. Four cases of the formation of intersectoral chains on the GDP matrix and the formulas describing the incremental growth of the innovative potential of a country: 0 - the formation of a GDP matrix; I and II - the $1^{\text {st }}$ and $2^{\text {nd }}$ cycles of the chain innovation transformation of the economy.

To demonstrate the potential of the proposed GDP matrix and CITE concept as a whole, we will briefly consider the economic miracles of Singapore, South Korea, and Hong Kong and the prospect of using this approach for countries that have not yet undergone industrialization. Also, we would like to emphasize that the proposed matrix allows us to determine the main sources of emerging ideas 
for CITE. This is confirmed by the history of the countries considered and the time periods over which their reforms occurred.

Analyzing the historical development of Singapore (Yeung, 2017), it can be noted that its economy has relied mainly on becoming and remaining competitive in the global market. Both local and foreign enterprises working in the sectors identified by the government as having priority (mainly industrial sector and sector of services, which correspond to the proposed matrix; Fig. 4) were historically encouraged and exempted from taxes. In the 1970s, these were oil refining, light industry, and shipbuilding, followed more recently by high technology and services. Companies engaged in these sectors of economy are currently exempted from duties and income tax for 5 years. As a result, 7 years in a row, Singapore has been called the best country in the world in which to do business. Despite the fact that there are no natural resources in Singapore, the country is the world leader in the production of platforms for oil mining in the open sea. The government is trying to determine which industries will in the future be the flagships of the global economy, and to invest heavily in them.

\begin{tabular}{|c|c|c|c|c|c|}
\hline 1 & 3 & 5 & 6 & 4 & 2 \\
\hline 45.5 & 16.5 & 5.0 & 0.037 & 11.8 & 21.1 \\
\hline Services & Trade & Construction & Agriculture & Transport & Industry \\
\hline
\end{tabular}

Fig. 4. The matrix of the structure of the economy of Singapore $(\% ; 2016)$.

Consider, for example, the Keppel Corporation, which is a Singaporean conglomerate. The company consists of several subsidiaries specializing in the management of marine, property, and infrastructure assets. The company was founded in 1968 as a Keppel shipyard at the port of Keppel. The formation of such a conglomerate is justified by the structure of the Singapore GDP matrix, and the emergence of innovations in shipbuilding and their final capitalization through the provision of services (via passenger and cargo ships) freed up additional resources for innovations, thus creating a new matrix of innovations (Fig. 5).

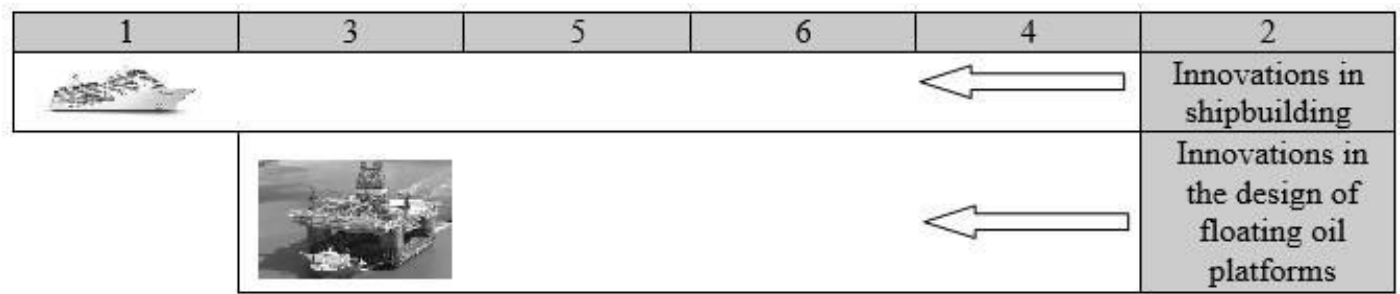

Fig. 5. CITE in the structure of the economy of Singapore.

Again, a sector of industry initiated the process based on the created opportunity matrix, which was successfully completed in the form of finished products (floating oil platforms) that are successfully sold by the trade sector. Keppel Offshore \& Marine became the world's largest producer of floating oil platforms (Brazinsky, 2007), demonstrating a classic example of CITE (Fig. 3, $1^{\text {st }}$ case). Two innovations (one in the design of floating oil platforms and another in shipbuilding) were aimed at obtaining hi-tech floating systems and were equally capable of combining sectors of the economy to obtain them. As a result, one product launched the formation of another. It is obvious that most sectors (3-trade $\uparrow, 5$-construction $\uparrow, 6$-agriculture $\downarrow$, and 4transport $\uparrow$ ) actively participate in the creation of both 
innovative products (ships and floating oil platforms), which gave them the opportunity to gain more skills and abilities.

Due to historical processes, a similar matrix was also formed in South Korea (Fig. 6). There are no mineral resources in the country, so exporting resources to replenish the budget was not an option initially considered. Because of South Korea's small land area, comprised mainly of mountainous territory, it was also difficult to actively develop agriculture. In the 1970s, when the country could not provide itself with agricultural products, let alone export them, the share of agricultural products in GDP was nearly $28 \%$. After the Korean War in the 1950s, almost all of the industry remained in the territory of North Korea. In South Korea, the development of the economy lagged because of a chronic lack of highly qualified engineers and workers. Almost the entire population of the country was poor and illiterate.

During the Vietnam War, South Korea supported the United States, which was a decisive step in its subsequent development. For this support, South Korea received tens of billions of dollars from the United States in the form of grants, loans, subsidies, and technology transfers.

\begin{tabular}{|c|c|c|c|c|c|}
\hline 1 & 3 & 5 & 6 & 4 & 2 \\
\hline 40.5 & 11.4 & 5.7 & 2.2 & 7.3 & 32.9 \\
\hline Services & Trade & Construction & Agriculture & Transport & Industry \\
\hline
\end{tabular}

Fig. 6. The matrix of the structure of the economy of South Korea $(\% ; 2016)$.

South Korean corporations also received large orders from the United States for the construction, transportation, repair, and maintenance of military equipment, etc. Analyzing the economic development of Singapore and South Korea, we can conclude that the matrix of opportunities they 'borrowed', that is, gained through cooperation with the United States, provided them with practices and technologies that aided in the development of many sectors of their economies. However, we consider the main merit of this to be that, by borrowing a matrix of opportunities, they were able to generate their own innovative ideas. The economy of South Korea was based on chaebols (a form of financial industrial groups), among the largest of which are Samsung, LG Group, Hyundai, Daewoo, and others. The emergence of such business structures is not a random occurrence in the GDP matrix of South Korea, but rather an innovation in the shaping of the industry, which allowed the launch of new opportunity matrices in the economy. With respect to the enterprise and product level, we can see from the example of the Samsung Group (Fig. 7) that chaebols, like the fractal of the GDP matrix of the whole country, include in themselves all the sectors of its economy (Ström, 2016).

\begin{tabular}{|c|c|c|c|c|c|}
\hline 1 & 3 & 5 & 6 & 4 & 2 \\
\hline $\begin{array}{l}\text { Samsung Life } \\
\text { Insurance } \\
\text { Samsung Fire } \\
\text { \& Marine } \\
\text { Insurance } \\
\text { Samsung Card } \\
\text { The Shilla } \\
\text { Hotels \& } \\
\text { Resorts }\end{array}$ & $\begin{array}{l}\text { Samsung } \\
\text { Everland }\end{array}$ & $\begin{array}{l}\text { Samsung } \\
\text { Electronics }\end{array}$ & $\begin{array}{l}\text { Samsung } \\
\text { Electronics }\end{array}$ & $\begin{array}{l}\text { Samsung } \\
\text { Electronics } \\
\text { Samsung } \\
\text { SDI } \\
\text { Samsung } \\
\text { Electro- } \\
\text { Mechanics }\end{array}$ & $\begin{array}{c}\text { Samsung Heavy } \\
\text { Industries } \\
\text { Samsung Total } \\
\text { Petrochemicals } \\
\text { Samsung } \\
\text { Petrochemicals }\end{array}$ \\
\hline Services & Trade & Construction & Agriculture & Transport & Industry \\
\hline
\end{tabular}

Fig. 7. Branches within the structure of the Samsung Group. 
When considering the structure of the Samsung Group, it should be noted that the company's aim was to occupy key positions in strong sectors of the economy, allowing them to generate innovations and capitalize on them. A big innovative leap in the development of computer electronics enabled the concomitant development of high-precision measuring equipment (Fig. 8). The emergence of computers and their final capitalization through the provision of private and government services (white arrow) freed up additional resources for innovations, thus creating a new matrix of innovations. Historically, the sector of services has always sought to personalize industry innovations and take into account the desire of each individual. The new matrix of innovations (white arrow) generated the innovative ideas in high-precision measuring equipment (gray arrow), particularly in medicine, and the sector of industry became the last link forming the end-product. Again, this is a classic example of CITE (Fig. 3, $2^{\text {nd }}$ case), when both innovations (in high-precision measuring equipment and computer electronics) constantly complement one another and the formation of opportunity matrices in one direction always fosters the formation of opportunity matrices in the other. Purchasing newer, more technologically sophisticated computers, for example, will help doctors and researchers discover further applications for their use in medicine. Conversely, the demand for high-precision measuring equipment, for example for use in brain research, will result in the need for more powerful computers based on existing prototypes. Again, it is obvious that most sectors (3-trade $\uparrow, 5$ construction $\uparrow, 6$-agriculture $\downarrow$, and 4-transport $\uparrow$ ) actively participate in the creation of innovative products in every innovative cycle, which gives them the opportunity to gain more skills and abilities. Of note, in every innovative cycle each sector of the economy grows innovatively according to its nature. For example, the sector of services will never be able to develop computer electronics, but will help it evolve by generating new ideas for the industry sector. In turn, the industry sector will never be sensitive to the needs of the individual consumer without the help of the service sector, but by making end-products, it will create the basis for personalized innovations. As a result, more general innovative products will be formed in the direction of the white arrow, and more personalized products will be formed in the direction of the gray one. This is exactly what happens in real life. Since such innovation growth is described by formula $3^{\text {n }}$ (Fig. $3,2^{\text {nd }}$ case), we predict a very rapid growth of innovation in the fields of computer electronics and high-precision measuring equipment in the near future.

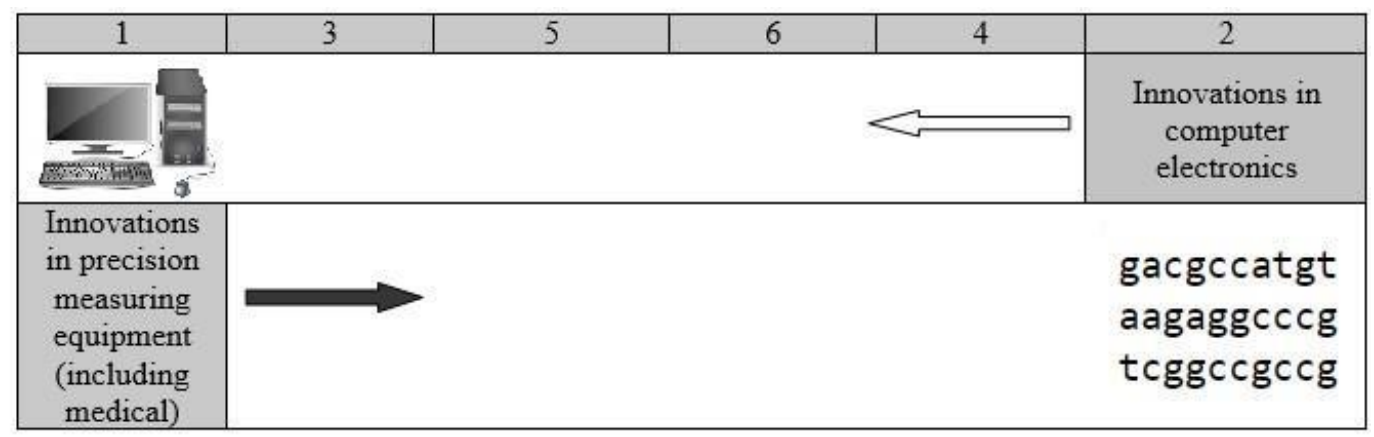

Fig. 8. CITE in the structure of the economy of the Samsung Group.

Having similarly limited natural resources in common with the previous two countries, but with a significant dominance of industry in the structure of the GDP in the 1970s, Hong Kong made a qualitative reformatting decision to move in the direction of trade and services. Its proximity to China, with its vast consumer market, prompted this move, since it was not possible to compete with China's 
$8^{\text {th }}$ International Conference on Management, Economics and

Humanities

7 - 9 December, 2018

Barcelona, Spain

growing industry. Based on these features, the GDP matrix in Hong Kong today has sectors of trade and services at its edges (Fig. 9).

\begin{tabular}{|c|c|c|c|c|c|}
\hline 1 & 3 & 5 & 6 & 4 & 2 \\
\hline 57.1 & 10.0 & 2.6 & 0.067 & 4.7 & 25.6 \\
\hline Services & Transport & Industry & Agriculture & Construction & Trade \\
\hline
\end{tabular}

Fig. 9. The matrix of the structure of the economy of Hong Kong (\%; 2016).

According to $1^{\text {st }}$ and $2^{\text {nd }}$ principles of the CITE concept, the structure of a full GDP matrix does not eliminate the possibility that other variations of intersectoral interactions will provide the new shortened matrices of opportunities that are the most profitable for the country's economy. For example, the company Hutchison Whampoa, which initially specialized in retail (trade sector), began to develop a sector of services $(2 \rightarrow 1)$. The sector of services triggered a surge in innovation in telecommunications, which are needed for negotiations, and insurance services, which are directly associated with conducting trade activities $(1 \rightarrow 2)$. This situation refers to the $2^{\text {nd }}$ case of CITE (Fig. 3 ) and is reflected in the capitalization of companies such as AIA Group (the largest insurance company in Hong Kong, the market value of which is almost \$36 billion) and China Mobile Communications Corporation headquartered in Hong Kong (the largest mobile operator in the world, with a capitalization of $\$ 240$ billion) (Li, 2014). Thus, a shortened GDP matrix, containing the sectors of services and trade, initiated chain innovative transformation of Hong Kong's economy; the share of products in GDP from these sectors is $82.7 \%$. The sectors found in the middle of the GDP matrix (transport $\uparrow$-industry $\downarrow$-agriculture $\downarrow$-construction $\downarrow$ ) passively participate in the creation of innovative products for the sectors of trade and services. In other words, for geopolitical reasons, Hong Kong today does not need to develop the weaker sectors of its economy. However, such uneven development of sectors is not a long-term sign of economic sustainability.

After analyzing the history of the economic successes of the countries presented, their initial levels of development, and the subsequent rates of economic growth, we can confidently say that the GDP matrix can become a kind of development pattern for those countries that have not yet undergone evolutionary turns of industrialization in their history. Primarily, we are talking about African countries that, by using variations of GDP matrices, can simulate the path of their economic development, thus avoiding known failed decisions and reforms, saving precious time and resources for themselves, and solving the fundamental contradiction between the wealth of owners and the increase in the quality of life of employees. Having formed a sufficient level of development (legal, social, economic), such countries will be able to decide on which way the form of the matrix of opportunities should go: to develop it independently or to 'borrow' successful opportunity matrices of other countries.

\section{Conclusion}

Summarizing the results of the study, we can draw the following conclusions.

1. Using technologies drawn from natural systems, it was demonstrated that there exists a similarity between the process of formation of GDP in national economies and the formation of a target amplicon in the polymerase chain reaction. The GDP matrix and CITE concept open up great opportunities for modelling the sustainable development of national economic systems. It is important to note that PCR is nothing more than an analogy for the CITE concept. The CITE concept and PCR 
$8^{\text {th }}$ International Conference on Management, Economics and

Humanities

7 - 9 December, 2018

Barcelona, Spain

each has its own different peculiarities, but an analogous topological scheme describes both of these processes.

2. The procedure for ranking industries in the structure of the matrix allows creation of a set of opportunity matrices. This in turn allows identification of the optimal combination of matrices, development of new industry structures, and elimination of erroneous solutions, leading to further sustainable development. In addition, in the course of the study, different formulaic representations of the GDP matrix increment were obtained, which allow consideration and modelling of vast variations of economic processes. In our opinion, using the developed method, as it was shown for the economic miracles of Singapore, South Korea, and Hong Kong, one can with a sufficient level of confidence anticipate the emergence of the basic chains of innovative transformations of global economies in the future.

\section{References}

1. Saiki RK, Gelfand DH, Stoffel S, Scharf SJ, Higuchi R, Horn GT, Mullis KB, Erlich HA: Primer-directed enzymatic amplification of DNA with a thermostable DNA polymerase. Science 239: 487-491 (1988).

2. Henry Wai-chung Yeung: State-led development reconsidered: the political economy of state transformation in East Asia since the 1990s, Cambridge Journal of Regions, Economy and Society, Volume 10, Issue 1, 1 March 2017, Pages 83-98.

3. Gregg Brazinsky. Nation Building in South Korea: Koreans, Americans, and the Making of a Democracy. (The New Cold War History.) Chapel Hill: University of North Carolina Press. 2007.

4. Patrik Ström: Dynamics of economic spaces in the global knowledge-based economy-theory and East Asian cases, Journal of Economic Geography, Volume 16, Issue 3, 1 May 2016, Pages 779-780.

5. Peng-Fei Li: Global temporary networks of clusters: structures and dynamics of trade fairs in Asian economies, Journal of Economic Geography, Volume 14, Issue 5, 1 September 2014, Pages 995-1021. 